\title{
Low Ambient Temperature Lowers Cholecystokinin and Leptin Plasma Concentrations in Adult Men
}

\author{
Monika Pizon, Przemyslaw J. Tomasik*, Krystyna Sztefko and Zdzislaw Szafran
}

Department of Clinical Biochemistry, University Children`s Hospital, Krakow, Poland

\begin{abstract}
Background: It is known that the low ambient temperature causes a considerable increase of appetite. The mechanisms underlying the changes of the amounts of the ingested food in relation to the environmental temperature has not been elucidated. The aim of this study was to investigate the effect of the short exposure to low ambient temperature on the plasma concentration of leptin and cholecystokinin.

Methods: Sixteen healthy men, mean age $24.6 \pm 3.5$ years, BMI $22.3 \pm 2.3 \mathrm{~kg} / \mathrm{m}^{2}$, participated in the study. The concentrations of plasma CCK and leptin were determined twice - before and after the $30 \mathrm{~min}$. exposure to $+4{ }^{\circ} \mathrm{C}$ by using RIA kits.

Results: The mean value of CCK concentration before the exposure to low ambient temperature was $1.1 \mathrm{pmol} / \mathrm{l}$, and after the exposure $0.6 \mathrm{pmol} / \mathrm{l}$ ( $<0.0005$ in the paired t-test). The mean values of leptin before exposure $(4.7 \pm 1.54 \mu \mathrm{g} / \mathrm{l}) \mathrm{were}$ also significantly lower than after the exposure $(6.4 \pm 1.7 \mu \mathrm{g} / \mathrm{l} ; \mathrm{p}<0.0005$ in the paired t-test). However no significant correlation was found between CCK and leptin concentrations, both before and after exposure to low temperature.

Conclusions: It has been known that a fall in the concentration of CCK elicits hunger and causes an increase in feeding activity. Also fall of leptin concentration may be one of the factors responsible for the enhancement of appetite. It has been concluded on the basis of this study that CCK and leptin participates in the short-term regulation of energy balance following exposure to low temperature by potentiating the feeling of hunger.
\end{abstract}

Keywords: Cholecystokinin, leptin, acute cold, environmental temperature, metabolism.

\section{BACKGROUND}

The amount of the ingested food is regulated in healthy individual by feelings of hunger and satiety. In hypothalamus there are two contrariwise interacting centers: hunger center (nucleus ventrolateralis) in the lateral part of hypothalamus and satiety center in the ventromedial nucleus. In physiological conditions, hunger center and satiety center remain in dynamic balance. The activity of these two centers is modified by several central and parenteral factors, the hormones, cholecystokinin (CCK) and leptin, among others.

CCK is an enterohormone belonging to the gastrin family. It is synthesized and secreted by the I cells localized mainly in the jejunum in response to food stimuli. In gastrointestinal tract CCK regulates mainly the motility and contraction of smooth muscles, and acts as a potent stimulant of secretion of pancreatic enzymes. CCK also participates in the central and parenteral regulation of feeding process [1]. Parenterally, CCK acts on diminishing the amount of the ingested food through the activation of the CCK-A receptors and following increase in the efferent impulsion of vagus nerve to the central nervous centers [2]. The parenteral effect is additionally intensified by the relaxation of gastric muscles. In turn, CCK acts centrally by directly stimulating hypothalamic CCK-B receptors [3]. Gibbs et al. [4] observed

*Address correspondence to this author at the Department of Clinical Chemistry, University Children`s Hospital, Wielicka St 265, 30-663 Krakow, Poland; Tel: ++48126580681; Fax: ++48126580681;

E-mail: mitomasi@cyf-kr.edu.pl that in rats CCK administered parenterally lowers the amount of the ingested food. In animal experiments, intraventrical administration of CCK receptor antagonists or specific antibodies increases feeding activity [2].

Leptin, a hormone synthesized mainly by white adipose tissue, has the structure similar to that of cytokines. Blood plasma concentration of leptin depends directly on adipose tissue mass and correlates with body mass index (BMI) [5] . It is thought that leptin plays a role of peripheral signal informing on the cumulated body stores of energy and thus participating in the long-term regulation of the amount of ingested food [6]. Acting at the level of central nervous system, leptin lowers the amount of ingested food by inhibiting the expression of neuropeptide Y (NPY) and the peptide bound to the agouti protein (AGRP). It also activates the expression of proteins connected with the propiomelanocortin group (POMC) [7].

It is known that the environmental temperature influences the amount of ingested food. Exposure to high ambient temperature results in the reduction of the amount of ingested food. Low ambient temperature, in term, causes a considerable increase of appetite. For the time being, the mechanism underlying the changes of the amounts of the ingested food in relation to the environmental temperature has not been elucidated. CCK and leptin are one of humoral factors, which could be involved in the regulation of appetite due to changes of environmental temperature. Therefore the aim of this study was to investigate the effect of the short exposure 
to low ambient temperature on the blood plasma concentration of leptin and cholecystokinin.

\section{MATERIAL AND METHODS}

Sixteen healthy men, mean age $24.6 \pm 3.5$ years, BMI $22.3 \pm 2.3 \mathrm{~kg} / \mathrm{m}^{2}$, participated in the study. The subjects were placed in the cold room for $30 \mathrm{~min}$ at the temperature of $+4{ }^{\circ} \mathrm{C}$. At the time of exposure to the low temperature, the subjects were dressed in light clothing: trousers, shirt and sweater. The subjects were after overnight fast and the experiment was done in the morning. The venous blood was taken from the antecubital vein to the cooled tubes containing EDTA and aprotinin (Sigma) twice - before and after the exposure. Blood was immediately centrifuged and plasma distributed to several tubes according to the assay plan, and frozen at $-70{ }^{\circ} \mathrm{C}$, until assayed. The day after, control experiment was performed with the participation of the same subjects at room temperature $\left(21^{\circ} \mathrm{C}\right)$ by applying the same protocol.

The concentrations of CCK and leptin were determined by using RIA kits (Eurodiagnostica, Sweden, for CCK, and Linco Research, Inc., USA, for leptin determination). The sensitivity of CCK assay was $0.3 \mathrm{pmol} / 1$ with precision (CV) $<5 \%$, that of leptin assay $0.5 \mathrm{ng} / \mathrm{ml}$ with precision $<10 \%$.

The results were subjected to statistical analysis. Mean values were compared by applying the paired t-test, with the probability $\mathrm{p}<0.05$ considered as a proof of significance. Correlation coefficients were calculated by using the parametric approach. All statistical calculations were done with the use of Statistica 5.0 and Excel 98 software.

\section{RESULTS}

The mean value of CCK concentration before the exposure to low temperature was $1.1 \mathrm{pmol} / \mathrm{l}$, and after the expo-
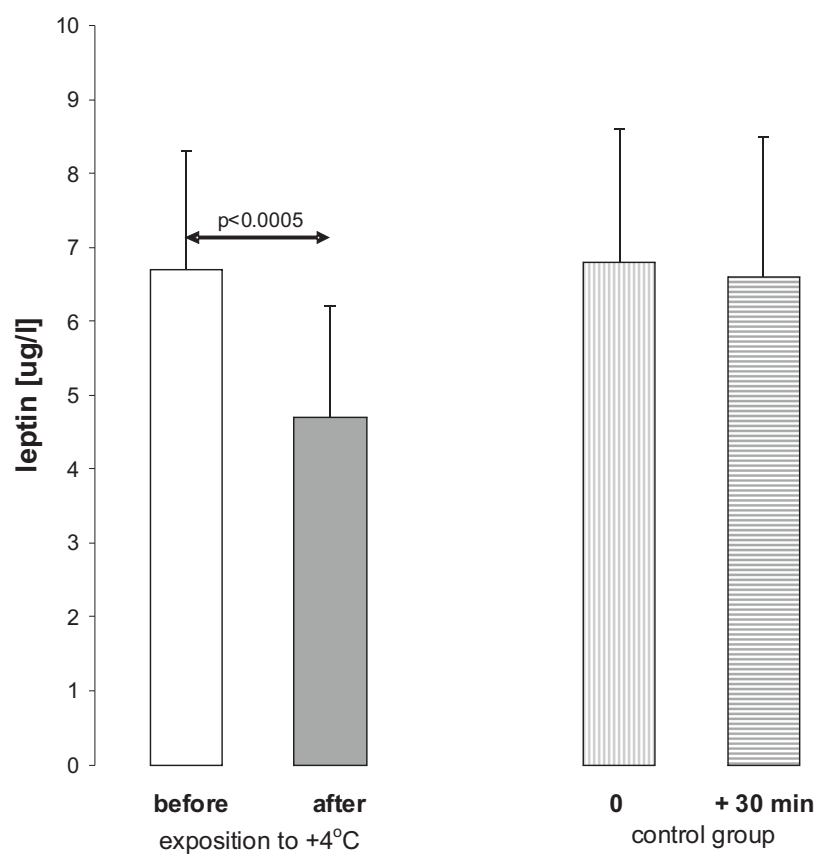

Fig. (1). Mean values of plasma CCK concentrations in patients treated acute cold (4 centigrade) and in room temperature. The statistical difference is between individual results by applying paired t-test. sure $0.6 \mathrm{pmol} / 1$ (Fig. 1). The difference between individual results being highly significant $(\mathrm{p}<0.0005$ in the paired $\mathrm{t}-$ test). The individual values of leptin concentration following exposure to low temperature were significantly lower as compared to the values before the exposure $(\mathrm{p}<0.0005$ as obtained in the paired t-test). The mean values were $4.7 \pm$ $1.54 \mu \mathrm{g} / \mathrm{l}$ and $6.4 \pm 1.7 \mu \mathrm{g} / \mathrm{l}$, respectively (Fig. 2). In the control experiment no significant changes neither in leptin nor CCK concentrations were observed (Fig. 1 and 2).

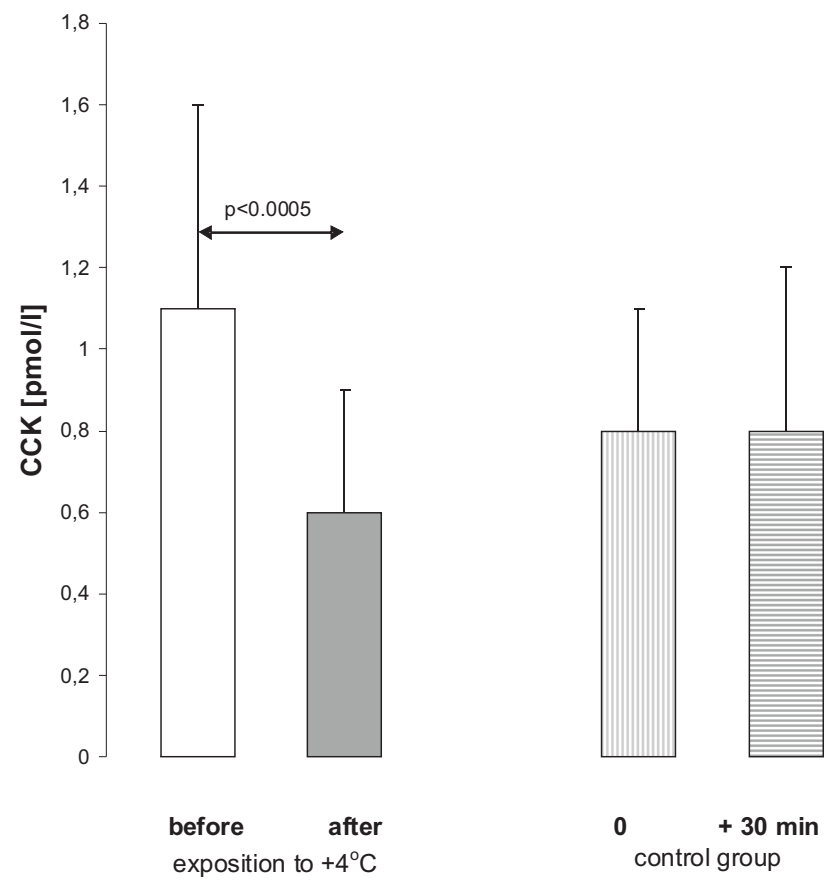

Fig. (2). Mean values of plasma leptin concentrations in patients before and after exposition to cold ( 4 centigrade). The statistical difference is between individual results by applying paired t-test.

No significant correlation was found between CCK and leptin concentrations, both before and after exposure to low temperature.

\section{DISCUSSION}

The thermostatic theory of appetite is based on the observation that high ambient temperature inhibits appetite and motor activities in animals. Exposure to low temperature elicits hyperphagia and considerably increases motor activity of the organism [8]. Recent studies confirmed a short-term limitation of the amount of ingested food under the influence of high environmental temperature [9]. The mechanisms underlying the changes in the amount of ingested food in relation to the ambient temperature have not yet been elucidated.

The results of the present study demonstrated a statistically significant decrease in the plasma concentration of CCK $(\mathrm{p}<0.0005)$ after a short exposure to low temperature. It has been concluded on the basis of this observation that CCK participates in the short-term regulation of energy balance following exposure to low temperature by potentiating the feeling of hunger and thus increasing the amount of the ingested food. It has been known that a fall in the concentration of CCK elicits hunger and causes an increase in feeding activity [2]. The mechanism of this phenomenon may be 
both peripheral and central. There could be down regulation of central CCK-B receptors as well as peripheral CCK-A receptors that in term activate vagus nerve [10].

The available data on the effect of low temperature on leptin secretion are controversial. The experiments of Hardie et al. and Cancello et al. suggest that short exposure to low temperature decreases the secretion of leptin in non-obese mice $[11,12]$. On the other hand, according to Melnyk et al. and Bing et al. long-term exposure to low temperature has no effect on leptin secretion in non-obese mice [13,14]. In humans it was observed that an elevated body temperature caused a decrease in leptin concentration, while a fall of body temperature brought about an increase in the concentration of this hormone $[15,16]$. It was also observed that low temperature causes a decrease in the blood serum concentration of leptin in healthy women [17]. Also the results of this study demonstrated a significant $(\mathrm{p}<0.0005)$ decrease in leptin concentration in healthy men after a short exposure to low ambient temperature confirming the view that this hormone may participate in the short-term regulation of energy metabolism [18]. In as much as also fasting lowers the concentration of leptin, the observed fall of leptin concentration following the exposure to low temperature may be one of the factors responsible for the enhancement of appetite observed in low environmental temperature. This fall may originate from the activation of the sympathetic nervous system. Low ambient temperature stimulates $\beta$-3-adrenergic receptors thus increasing cellular concentration of cyclic AMP that leads to a decrease of leptin synthesis by adipocytes [19].

\section{CONCLUSION}

The leptin and CCK are involved in adaptation to shortterm acute cold exposure.

\section{REFERENCES}

[1] Pekin S. Role of CCK in control of food intake. Gastroenterol Clin North Am 1998; 18: 757-75.

[2] Rehfeld J. CCK and satiety signal. Int J Obes 1991; 5: 465-9.
[3] Wank S. Cholecystokinin receptors. Am J Physiol 1995; 269: 62846.

[4] Gibbs J, Young RC, Smith GP. Cholecystokinin decreases food intake in rats. J Comp Physiol Psychol 1973; 84 : 488-95.

[5] Maffei M, Halaas J, Ravussin E, et al. Leptin levels in human and rodent: measurement of plasma leptin and ob RNA in obese and weight -reduced subject. Nat Med 1995; 1: 1155-61.

[6] Ahima SR, Flier JS. Leptin. Annu Rev Physiol 2000; 62: 413-37.

[7] Friedman JM. Obesity in the new millennium. Nature 2000; 404: 632-4.

[8] Brobeck JR. Food intake as mechanism of temperature regulation. 1948 (classical article). Obes Res 1997; 5: 641-5.

[9] Westerterp-Plantenga MS, Verwagen CR, Ijedema MJ. Acute effects of exercise or sauna on appetite in obese and nonobese man. Physiol Behav 1997; 62: 1345-54.

[10] Wank SA. Cholecystokinin receptors. Am J Physiol 1995; 269: 628-46.

[11] Reidelberg RD. CCK and control of food intake. J Nutr 1994; 124 : 1327-33.

[12] Hardie LJ, Rayner DV, Holmes S, Trayhurn P. Circulating leptin levels are modulated by fasting, cold exposure and insulin administration in lean but not Zucker (fa/fa) rats as measured by ELISA. Biochem Biophys Res Commun 1996; 223(3): 660-5.

[13] Cancello R, Zingaretti MC, Sarzani R, Ricquier D, Cinti S. Leptin and UCP1 genes are reciprocally regulated in brown adipose tissue. Endocrinology 1998; 139: 4747-50.

[14] Melnyk A, Himms-Hagen J. Temperature-dependent feeding: lack of role for leptin and defect in brown adipose tissue-ablated obese mice. Am J Physiol 1998; 274(4 Pt 2): R1131-5.

[15] Bing C, Frankish HM, Pickavance L, et al. Hyperphagia in coldexposed rats is accompanied by decreased plasma leptin but unchanged hypothalamic NPY. Am J Physiol 1998; 274(1 Pt 2): 62-8.

[16] Simon C, Gronfier C, Schlienger JL, Brandenberger G. Circadian and ultradian variations of leptin in normal man under continuous enteral nutrition: relationship to sleep and body temperature. J Clin Endocrinol Metab 1998; 83: 1893-9.

[17] Ricci M, Fried S, Mittelman K. Acute cold decrease plasma leptin in woman. Metabolism 2000; 49: 421-3.

[18] Friedman JM, Halaas JL. Leptin and the regulation of body weight in mammals. Nature 1998; 395: 763-70.

[19] Peino R, Pineiro V, Guaillo O. Cold exposure inhibits leptin secretion in vitro by a direct and non-specific action on adipose tissue. Eur J Endocrinol 2002; 142: 195-9. (http://creativecommons.org/licenses/by-nc/3.0/) which permits unrestricted, non-commercial use, distribution and reproduction in any medium, provided the work is properly cited. 